\title{
Sofía Casanova en la I Guerra Mundial: una reportera en busca de la paz de la guerra
}

\author{
Asunción BERnÁRDEZ RoDAL \\ Universidad Complutense de Madrid \\ asbernar@ccinf.ucm.es
}

Recibido: 23 de julio de 2013

Aceptado: 13 de septiembre de 2013

\section{Resumen}

En este texto se analiza el trabajo periodístico de Sofía Casanova como reportera en el frente oriental (Polonia) en la I Guerra Mundial. Su objetivo es destacar las ideas pacifistas que la autora va exponiendo en las crónicas escritas para el diario $A b c$ y que fueron publicadas de forma conjunta en 1916 bajo el título De la guerra. Crónicas de Polonia y Rusia. Se explicará el sentido de esta obra no solo a través del contexto biográfico de la autora, sino que se utilizará el entorno ideológico de la Europa del momento para explicar que el pacifismo de Casanova no es está alejado de los movimientos sociales o del pensamiento de su época.

Palabras clave: Periodismo; I Guerra Mundial; Feminismo; Sofía Casanova; Pacifismo.

\section{Sofía Casanova in World War I: a reporter looking for "the peace of war"}

\begin{abstract}
In this paper we analyze the journalistic work of Sofia Casanova as a reporter on the Eastern Front (Poland) in the First World War. The objective of this paper is to highlight the pacifist ideas that the author is exposing in the chronicles written for the daily $A B C$ and were published together in 1916 under the title From the War: Chronicles of Poland and Russia I. The meaning of this journalistic work is going to be explained not only through the author's biological context but also the ideological context of Europe at that time, which will enable us to understand that her pacifism does not mean that Casanova is far from the social movements or thought of her time.
\end{abstract}

Keywords: Jornalism; World War I; Feminism; Sofía Casanova; Pacifism.

\section{Referencia normalizada}

Bernárdez Rodal, A. (2013) Sofía Casanova en la I Guerra Mundial: una reportera en busca de la paz de la guerra. Historia y Comunicación Social. Vol. 18, págs. 207-221.

Sumario: 1. Introducción. 2. Semblanza biográfica. 3. La prensa y mujeres periodistas a principios del siglo XX. 4. Movimientos de mujeres en España y Pacifismo. 5. Las dos condiciones "identitarias" del pacifismo de Sofía Casanova: el catolicismo y su condición de mujer. 6. El papel de las mujeres en las guerras. 7. Conclusiones. 8. Bibliografía. 


\section{Introducción}

La figura de Sofía Casanova sólo es conocida bien por aquellas personas que se interesan por indagar la presencia de las mujeres en la historia de la prensa española, o bien por aquellas otras que se dedican a rescatar la historia de Galicia a través de sus personajes ilustres. Su biografía personal y literaria está condenada a ser escrita en los "márgenes", no sólo de las crónicas gloriosas de la belicosa Europa, sino también de la historia del periodismo español. A Sofía Casanova se la presenta como "la primera reportera de la historia del periodismo en España”. Pocas veces, se va más allá para analizar qué aportó al quehacer periodístico o literario, o incluso, al pensamiento pacifista y antimilitarista en España.

En los últimos tiempos se han publicado muchos trabajos sobre la vida y la obra de Sofía Casanova (Alayeto, O. 1992; Bugallal y Marchesi, J.L. 1964; Hooper, K. 2008; Martínez Martínez, R. 1999; Osorio, O. 1997; Pazos, A. (Coord.) 2010) tanto el contexto español como en el americano. Se trata de trabajos en su mayoría muy interesantes que tienen el objetivo de rastrear o bien una biografía que complete el panorama intelectual español de principios de siglo, y de forma más concreta, aclare el significado de la participación de algunas mujeres en los procesos históricos contemporáneos.

Nuestro trabajo está planteado de una forma más concreta, ya que pretende centrarse sólo en un aspecto de Sofía Casanova: el desarrollo de sus ideas pacifistas frente a las guerras, que ella argumenta a partir de dos condiciones de experiencia personal: su cristianismo y su condición de mujer. El corpus de nuestro trabajo no será toda su obra, sino el texto donde la autora expone sus ideas pacifistas que son $D e$ la guerra. Crónicas de Polonia y Rusia publicada en 1916 en la que se recogen los artículos publicados en prensa desde el inicio de la guerra. También se hará referencia a un pequeño texto que recoge una conferencia pronunciada en el Ateneo de Madrid en 1919 frente a un auditorio de militares: "Impresiones de una mujer en el frente Oriental de la guerra europea", en la que aparecen expuestas con contundencia sus ideas sobre la necesidad de la negociación pacífica y el trabajo por la paz.

\section{Semblanza biográfica}

La biografía de Sofía Casanova tiene tanto de convencional como de extraordinaria. Nacida en La Coruña, en 1861, es una mujer que se educa en un contexto decimonónico pero que escribe y opina de las contiendas que desgarraron Europa en la primera mitad del siglo XX. Cuando muere en Polonia, en 1958, había publicado novelas, cuentos, poesía, múltiples cartas, una obra de teatro e infinidad de crónicas sobre los sucesos más dramáticos que durante cincuenta años habían marcado Europa, y que supusieron una auténtica recomposición del mundo desde que ella había nacido: la I Guerra Mundial, la Revolución Rusa y la II Guerra Mundial. Publicó sus crónicas en los periódicos más importantes del Madrid de la época, como $\mathrm{Abc}$, La Época, El 
Mundo, El Imparcial. También en prensa internacional, como The New York Times. Sin embargo, como se comenta a menudo, no fue la primera mujer que escribe de forma directa sobre un conflicto bélico. El mérito le corresponde a su amiga Carmen de Burgos, Colombine, que cubrió de forma breve la guerra de Marruecos en 1909. Tampoco fue la "gallega universal" que a veces se pretende. Con hondas raíces en su Coruña natal, emigró a Madrid con catorce años y se casó con un escritor y pensador polaco a los veinticinco. Desde ese momento, comenzaron sus viajes por Europa acompañando a un marido de temperamento depresivo, y en una relación repleta de desencuentros. Él quiso abandonarla varias veces pero ella nunca le concedió el divorcio, pese a haber sufrido sus constantes reproches por no haberle dado hijos varones que asegurasen la continuidad patrilineal. Casanova pasó gran parte de su vida fuera de España, pero mantuvo siempre la relación con su patria, enviando información constante de lo que ocurría fuera de nuestras fronteras. Sus textos eran leídos y citados en muchos periódicos, lo que la convirtió en un personaje popular.

En esta biografía llena de contrastes, Sofía Casanova es una mujer con ideas del siglo XIX, que desarrolla su principal actividad literaria y productiva en el siglo XX. Es la mujer "bien casada" que sin embargo, tiene que trabajar de forma profesionalizada para mantener a sus hijas. Es una progresista del XIX, que como casi todas las mujeres posrománticas, asimila el modelo femenino de ser el "Ángel del Hogar" y que acaba resultando conservadora en el siglo XX. En definitiva, es una escritora que debe ser interpretada con las claves contradictorias de lo que fueron las luchas de las mujeres en la España del siglo XIX, cuando se reivindicaba la educación, la formación por encima del derecho al voto y de los derechos políticos, en contraste con lo que hacían las sufragistas en el ámbito anglosajón. En esa España ultra-católica de finales del siglo XIX era muy difícil que se dieran mujeres dispuestas a saltarse las convenciones marcadas por la religión. Como mucho, "disimulaban" su condición de mujeres intelectuales fingiendo hacer calceta mientras se reunían, escribían o debatían sobre todos los temas que podían interesar en la época. En el desgarramiento que supuso la emergencia del comunismo y en el fascismo en Europa, Casanova, ya una mujer mayor, se decantó públicamente por los gobiernos conservadores que prometían una estabilidad del mundo basada en la jerarquía social que reforzaba el catolicismo conservador.

Sofia Casanova fue lo que hoy podríamos denominar "pacifista", porque se niega a considerar razonable cualquier postura que defendiera la guerra como necesaria para el devenir humano. Para ella los conflictos bélicos son un producto de los hombres, de los gobiernos que permiten los "asesinatos colectivos legales" (1916: 36). Aunque ya había mostrado estas ideas cuando escribió sobre la guerra de Marruecos, la madurez de sus planteamientos se refleja en la publicación de las crónicas hechas desde Polonia y Rusia en los años iniciales de la I Guerra Mundial, y que fueron enseguida publicadas en un volumen recopilatorio, en 1916, bajo el título De la guerra. 


\section{La prensa y mujeres periodistas a principios del siglo $\mathrm{XX}$}

La historia de la participación de las mujeres en la prensa, como en otros ámbitos culturales, adolece de un cierto "pionerismo" en el peor sentido de la palabra. A toda creadora se la suele pintar como una "pionera" valiente y arrojada a la conquista de un mundo extraño y hostil a su temperamento. Sin embargo, esta pintura casi nunca es justa. A Sofía Casanova no debemos interpretarla como una "estrella solitaria" (Hooper, K. 2008: 12) porque desde el período romántico, existía una gran tradición de mujeres escritoras que habían ido ganando un espacio en las publicaciones del momento, con firmas tan significativas como Rosalía de Castro, Carolina Coronado o Emilia Pardo Bazán. En el trabajo de referencia de María del Carmen Simón Palmer (1991), Escritoras españolas del siglo XIX, aparecen contabilizadas más de 250 escritoras que encontraron su medio natural de publicación en la prensa periódica. Como afirman Perinat y Marrades (1980: 29), la prensa se había convertido en el medio natural donde las mujeres podían manifestar sus reivindicaciones, su "temple y su talento".

Cuando Sofía Casanova nace en 1861 en España se había ido formando a lo largo del siglo XIX una prensa conservadora dedicada a las mujeres, dirigidas por hombres y dedicadas a extender el ideal de "El Ángel de Hogar" con cabeceras como El Té de las damas, El Periódico de Damas, o El Defensor del Bello Sexo. Sin embargo, allí publicaban autoras tan importantes como Cecilia Böhl de Faber (Fernán Caballero) o Carolina Coronado. Esta prensa conservadora fue abriendo espacio para que pudieran surgir las primeras publicaciones periódicas dirigidas por mujeres como El Correo de la Moda (1851-1893), dirigida por Ángela Grasi, o la publicación La Violeta, de la que se hizo cargo Faustina Sáez de Melgar en 1862; sin olvidar tampoco, la importante figura de Pilar Sinués de Marco que dirigió El Ángel del Hogar y La moda elegante ilustrada.

Gracias a estas cabeceras en las décadas posteriores, es posible que vayan surgiendo publicaciones cada vez más alejadas de la mentalidad isabelina, como La voz de la caridad, fundada en 1870 por Concepción Arenal, y La Ilustración de la Mujer (1872-1884), fundada por Concepción Gimeno de Flaquer, con la intención explícita de defender los derechos de las mujeres. No debemos olvidar tampoco el inicio de la importante publicación de Emilia Pardo Bazán Nuevo Teatro Crítico (1891-1893), una revista literaria que tenía como fin explícito la "agitación social". Cuando Sofía Casanova con catorce años llega a Madrid, las publicaciones donde muchas mujeres de la burguesía encuentran un espacio como lectoras- como autoras o incluso como directoras son ya una realidad (Bernárdez, 2007: 24).

De lo que con toda probabilidad no participó Sofía Casanova, fue del desarrollo de la prensa femenina vinculada con los movimientos anarquistas y de izquierdas, ni de las publicaciones de cariz claramente feminista de las primeras décadas de los años 20 ya que abandonará España el año en que contrae matrimonio, 1887, viviendo a partir de ese momento su condición de "extranjera" en todas partes. Con su matrimonio deja su país, pero también tiene que dejar aparcadas temporalmente sus aficiones 
literarias: "El cambio de vida, la inestabilidad del hogar y el cuidado de mis hijas, enmudecieron mi musa de poetisa (...). He vivido veinte años entre España y Polonia, educando a mis tres hijas, enfermera de un marido enfermo, y cultivando la literatura con intervalos de años" (citado en Osorio, 1997: 29). Como para muchas mujeres, los cuidados de la familia, sumados a su situación de extranjera, marcan su falta de continuidad en las tareas literarias durante un periodo de tiempo extenso.

Cuando regresa a España en 1904, Casanova tiene cuarenta y tres años, y es entonces cuando comienzan sus colaboraciones en prensa. Mientras tanto, grandes cambios de mentalidad se están sucediendo. Cambios que Sofía Casanova va a ir asimilando, sin renunciar nunca a su catolicismo conservador. La autora se encuentra un panorama de mayor modernidad ideológica, pero en el que también comienza a percibirse una gran factura entre el pensamiento progresista y conservador. Roch Castellanos (1977: 57) afirma, por ejemplo, que en esos momentos, la prensa se divide en "femenina y feminista". Crecen las publicaciones vinculadas al movimiento obrero y al mismo tiempo, a los sectores católicos conservadores. Por ejemplo, Benita Asas Monterola es cofundadora de la publicación El Pensamiento Femenino, que sale a la calle en 1913, con un consejo de redacción formado sólo por mujeres de tinte conservador y humanitario, frente a la publicación más progresista La Voz de la Mujer (1917-1937), dirigida y fundada por Celsia Regis (seudónimo de Consuelo González Ramos), donde publicaron intelectuales del momento como Carmen Karr, Concha Espina, Blanca de los Ríos, Clara Campoamor o la propia Sofía Casanova. El entorno editorial que nos encontramos en las primeras décadas del siglo XX, está totalmente en relación con los movimientos sociales y políticos del momento. Sobre todo, en lo que a publicaciones de mujeres se refiere. A partir de 1904 volverá más a menudo a España en períodos cortos, pero siguió residiendo en Polonia cerca de la familia de su marido. Desde allí siguió escribiendo sus crónicas.

Cuando estalla la I Guerra Mundial, Casanova se encuentra en Polonia visitando a su hija y se queda aislada en un período largo sin recibir noticias de España, mientras que sigue escribiendo cartas que serán luego publicadas en prensa. Desde esos momentos la autora se convierte en una auténtica cronista que presta sus ojos al público español. Es una escritora reflexiva, que medita sobre su quehacer periodístico o sobre la división de la prensa española frente a los bandos en guerra. En los textos recogidos en su trabajo De la guerra (1916) comenta a menudo la situación de los diarios españoles frente al conflicto "La Prensa española, sometida a las influencias de unos y otros luchadores es la que conserva al menos más ecuanimidad" mostrando a la vez su extrañeza sobre cómo puede haber "tantos germanófilos en España" (1916:32). Al mismo tiempo que señala estos puntos parece reconocer de forma implícita la importancia de la prensa en la propaganda de la guerra, y habla de las mentiras "de unas y otras agencias" (1916: 36), mientras que ella "ve" el conflicto con sus propios ojos y cuenta lo que está ocurriendo. Es, pues, una cronista que lucha por mantener su visión objetiva sobre los sucesos que está viendo, que entiende su trabajo como una auténtica lucha por la ecuanimidad: "Combato las noticias escritas, discuto los hechos que me comunican, indago, deduzco, doy ejemplos de la barbarie 
de todos... de los raros casos magnánimos en unos u otros soldados (...) Y me duele la confusión, el recelo, el dolor de todos y el esfuerzo que hago equilibrándome, buscando el punto de apoyo de la verdad de la vorágine de nombres, cifras, muertes, martirios, sangre y llamas..." (1916:158) Es una periodista que manifiesta claramente desde dónde habla, y proporciona de forma muy abierta las claves para ser interpretada. Su voz es la de una periodista católica que sufre el desgarramiento de Polonia, su patria adoptiva, y se posiciona de una forma muy clara a favor de los aliados.

\section{Movimientos de mujeres en España y Pacifismo.}

No podemos decir que Sofía Casanova estuviera a la vanguardia del feminismo. Sí que estuvo en contacto personal con la primera generación de mujeres a las que podemos dar el adjetivo de "feministas", ya que participaron en las primeras organizaciones de este tipo desarrolladas en el contexto español (Martín Polín y Lerma Rueda, 2007). Sigue siendo útil para entender los orígenes del feminismo en España el trabajo de Scanlon (1986) en el que podemos leer que existieron a principios de siglo tres corrientes dentro del movimiento de liberación femenina: el feminismo católico, el moderado y el de izquierdas. Mientras el primero se organizó a partir de 1919, en torno a la denominada "Acción Católica de la Mujer", aprovechando el trabajo cooperativo de las mujeres en las parroquias, el de izquierdas había comenzado a formarse a partir de las organizaciones obreras como las Agrupaciones Femeninas Socialistas, fundada en 1902, así como las impulsadas más tarde en torno al Partido Comunista o al movimiento Anarquista, como fueron "Mujeres contra la Guerra y el Fascismo" de 1933 o las Mujeres Libres en los comienzos de la guerra en 1936. Sin embargo, el feminismo que obtuvo mayor visibilidad pública fue el que defendieron las intelectuales burguesas, a las que Scalon califica como "feministas moderadas" ya que no participaban de los ideales revolucionarios y se centraban en la consecución de derechos civiles y políticos para las mujeres. Para el feminismo moderado, fue muy importante la fundación de asociaciones como la Asociación Nacional de Mujeres Españolas en 1918, la Cruzada de las Mujeres Españolas, impulsada por Carmen de Burgos en 1921, o la Unión del Feminismo Español de 1924.

Sin duda para Sofía Casanova, el desarrollo del feminismo burgués organizado en los años 20 fue muy importante ya que estableció lazos muy estrechos con algunas de las mujeres que se situaban en las entonces modernas reivindicaciones del voto y la cultura femenina. Sin embargo, en 1923 cuando se publican dos de los textos feministas más importantes del momento, La condición social de las mujeres, de Margarita Nelken, y La mujer moderna y sus derechos, de Carmen de Burgos, Sofía Casanova es ya una mujer de 62 años. Aunque sólo es siete años mayor que Carmen de Burgos, su actitud madura y sus ideas independientes la distancian de las autoras que están llevando a cabo una revolución en el panorama intelectual español como María Lejárraga y María Goiri (nacidas en 1874), María de Maeztu (1881), Zenobia Camprubí (1887), Clara Campoamor (1888), Victoria Kent (1889), Matilde Hici (1890) o Margarita Nelken (1894). Por eso afirmábamos al principio que Sofía 
Casanova tendrá siempre un lugar "descentrado" dentro de los movimientos culturales en España: ya que está físicamente dentro y fuera del país, pero también está intelectualmente dentro y fuera de las ideas y los procesos sociales que se están llevando adelante en España. No podemos clasificarla en el feminismo católico pero tampoco militó en el feminismo de forma clara y contundente. De tal forma que sus discursos de género tienen la suficiente singularidad y la suficiente personalidad para ser objeto de estudios particulares que desvelen la encrucijada de una mujer culta, que desarrolla su vida entre dimensiones que pueden resultar paradójicas sólo a simple vista.

Una de esas dimensiones fue precisamente su postura pacifista, que la hace aparecer como un "personaje único en España" (Alayeto, 1992: 158), por haber expuesto públicamente en la prensa sus ideas contra la guerra, basadas en un catolicismo humanitario radical y en su particular proto-feminismo. Según su punto de vista la guerra es censurable porque es maligna y provocar la muerte es algo condenado por la religión. Dentro de este esquema de pensamiento católico hace una lectura de género del conflicto calificando a la violencia y a la agresividad como atributos propiamente masculinos. Es éste uno de los motivos para animar a las mujeres a luchar activamente contra la guerra.

Estas ideas que en las que Casanova basa su oposición a la guerra de pudieran parecernos hoy en día conservadoras, pero sin embargo, en la época, estaban muy lejos de serlo. Debemos recordar que, por ejemplo, el sufragismo americano brotó de las organizaciones de mujeres protestantes que apoyándose en los sentimientos humanitarios, comenzaron a organizarse en torno a los movimientos de liberación antiesclavistas. La Declaración de Seneca Falls de 1848, por ejemplo, comienza con una alusión a Dios en su "Considerando" inicial. Casanova, como hemos dicho, fue una mujer educada en el siglo XIX y para ella el principio ético-religioso de "Todos los hombres son hermanos" es el que debía regir la organización social. El feminismo, entendido como un movimiento organizado de mujeres por la lucha por conseguir la igualdad social, despegaría más tarde en España, cuando Casanova tiene cerca de sesenta años y una larga experiencia de vida residiendo en distintos lugares de Europa.

Aunque no sea éste el lugar para hacer una exposición sobre las implicaciones entre el movimiento feminista y el pacifismo, sí que consideramos interesante hacer un apunte sobre el tema, ya que ambas posiciones han estado interrelacionadas durante más de un siglo, tanto si pensamos en ambas categorías como movimientos sociales o como corrientes ideológicas. Estudiar qué conoció de estos movimientos Sofía Casanova y cómo se posicionó ante ellos es un trabajo todavía pendiente de realización, aunque contamos con alguna investigación aproximativa al problema (Lorenzo, 2007: 130).

Existe una idea popular y extendida de que las mujeres somos "naturalmente" más pacíficas y menos violentas que los varones. Ese principio ha ido tomando forma en las ideas post-ilustradas de forma más o menos explícita en el desarrollo de la teoría política a lo largo de dos siglos. Los ejemplos son muchos y nos detendremos sólo 
en relatar lo más llamativo de una historia que, por otro lado, aparece más bien silenciada cuando se habla de los movimientos políticos contemporáneos. Los ejemplos de la relación de las posturas feministas y el pacifismo están presentes desde el primitivo socialismo utópico, cuando en 1948, se constituyó un grupo de Mujeres saintsimonianas, que apelaban a la formación de un mundo nuevo al lado de los varones, donde pudiera reinar la paz. Otro ejemplo de esta relación lo tenemos en la propuesta de la activista sueca Frederika Bremen, quien abogó en 1854 por la formación de una Liga Pacífica durante la sangrienta guerra de Crimea. La mayor visibilidad pública de este movimiento fue la obtenida por Bertha von Suttner, la llamada "sufragista por la Paz", quien en 1889, publicó una novela de gran éxito, titulada ¡Abajo las armas!, que le valió el Premio Nobel de 1905. En ella se cuenta la guerra desde la perspectiva de una mujer. Aunque Von Suttner no sea propiamente feminista, expone sin reparos la diferencia de género respecto a la educación en la violencia: niños y niñas se educan en la admiración de las armas, pero las niñas deben renunciar a la gloria que proporciona el servicio de las mismas, que son las "más altas dignidades y los más granes honores" (1906: 11). Señalando de este modo lo paradójico de la situación femenina frente al uso de armas: su "feminidad" las obliga a estar en contra de la guerra, pero, al excluirse de ellas, renuncian a las glorias que otorga la sociedad a los varones que de una forma u de otra acaban imponiendo su ley por la fuerza. Así mismo entro del movimiento socialista hubo muchas mujeres que levantaron su voz en el Congreso Internacional de Mujeres de 1910, para "luchar contra la guerra". Fue precisamente en torno a la I Guerra Mundial, donde la cuestión del pacifismo cobró una gran importancia y visibilidad en la prensa. Por un lado, creció el apoyo femenino a las movilizaciones en pro de la paz, pero por otro, y en países tan implicados en la causa feminista como en Inglaterra se produjo una escisión (Ward, 2001), ya que algunas organizaciones pasaron a apoyar a sus gobierno en el conflicto ${ }^{1}$, poniendo en suspenso la reivindicación del sufragio para las mujeres.

No sabemos hasta qué punto Casanova siguió todos estos debates que fueron previos a la guerra. Sin embargo, no cabe duda que, como persona interesada que trabaja en prensa, habría conocido las manifestaciones públicas en pro de la paz que tuvieron lugar en Europa, o las manifestaciones de figuras tan importantes en el momento como fueron las de Bertrand Russell que permaneció encarcelado durante seis meses por sus artículos publicados en contra de un gobierno inglés a favor de la guerra en un debate que llegó a Estados Unidos o a la misma Alemania. Y es precisamente en torno a los inicios de la I Guerra Mundial, cuando se crean las principales agrupaciones de mujeres antibelicistas (Rius Gatelli, R. 2006) y que tendrán continuidad a lo largo del siglo XX (Magallón Portolés, C. 2000), y que serán una de las tendencias más activas desde entonces dentro del pensamiento feminista. 


\section{Las dos condiciones "identitarias" del pacifismo de Sofía Casanova: el catolicismo y su condición de mujer.}

Desde nuestra perspectiva post-sesentayochista, tendemos a leer el pacifismo como una corriente de pensamiento vinculada al anti-militarismo, y precisamente por eso puede resultarnos hoy extraño adjetivar a Sofía Casanova como pacifista conociendo sus declaraciones a favor del régimen de Franco, en un contexto de supuesta amenaza estalinista. Pese a todo, está claro que Casanova defendió en su tiempo la idea de que los estados no deben utilizar la guerra para resolver los conflictos. Las raíces a las que ella apela constantemente son católicas, y podemos encontrarlas en una tradición que ya existía en Europa y Estados Unidos. Por ejemplo, las bases del pacifismo alemán de Bertha von Suttner procedían, seguramente de la influencia americana, ya que era un país donde distintas sectas y grupos católicos habían planteado vivir de forma radical lo que identificaban como ideas del cristianismo primitivo. Fueron metodistas, cuáqueros y anabaptistas los primeros en fundar, a principios del siglo XIX, sociedades pacifistas como la American Peace Society, que fueron conocidas en Europa desde muy pronto.

Pero si una figura pudo influir en Sofía Casanova, por el contexto en el que vivió en Polonia, fue seguramente Leon Tolstoi, quien en la última etapa de su vida, levantó grandes pasiones con sus propuestas espirituales y una vuelta a una especie de misticismo cristiano primitivo. Tolstoi había sido, a su vez, un lector apasionado del americano Henry David Thoreau, quien en 1848 había publicado lo que sería un libro fundamental para la historia de la resistencia pacífica del siglo XX, dejando huella en figuras como Gandhi o Martin Luther King. Este texto era, en realidad, una conferencia de Henry David Thoreau que daría nombre a una conocida forma de resistencia pacífica: "La desobediencia civil". En ella, por ejemplo, argumentaba que estaba en su derecho de no pagar impuestos al estado, si éste los empleaba en la guerra. El trabajo de Thoreau fue tomado como base para las ideas pacifistas de Tolstoi, que las desarrollaría en su libro El reino de Dios está dentro de vosotros. Esta obra que en España fue traducida tardíamente con el título Cuál es mi fe, tuvo que ser originalmente publicada en Alemania, en 1894 al haber sido censurada en Rusia por proponer que el cristianismo se había alejado de las verdaderas enseñanzas de Cristo, quien promulgaba "la no resistencia al mal mediante el mal". No sólo la obra, sino también la figura de Tolstoi, fueron importantísimas en la Europa de finales del siglo XIX y principios del XX, en un momento donde la prensa escrita había adquirido una gran relevancia social, y se estaba gestando eso que hoy día, llamamos "opinión pública". Su muerte, en 1910, fue todo un acontecimiento nacional en Rusia, en el que las autoridades zaristas temieron una revuelta. El acontecimiento fue recogido por toda la prensa de toda Europa que señaló la importancia histórica del fallecimiento de Tolstoi; no sólo para el mundo literario, sino como autoridad pública y voz moral que no tenía miedo a hablar demandando la paz entre los pueblos, y que desde un punto de vista muy espiritual hablaba del reparto igualitario de los bienes en la tierra y de la perfección moral siguiendo las normas de Cristo. 
Cuando estalla la guerra en 1914, Sofía Casanova se encuentra en Polonia, tiene 53 años y es contratada por el $A b c$ para enviar información sobre el conflicto. El periódico contaba con corresponsales en toda Europa: Juan Pujol, José Ma Salaberría, Julio Camba o Juan José Cárdenas enviaban sus crónicas, pero ninguna se aproxima a la experiencia contada por Sofía Casanova que narra el conflicto mientras está trabajando como enfermera destinada en la Estación de Viana, donde atiende a los heridos más graves durante todo un año. Desde ese lugar nos cuenta los horrores que está viendo con sus propios ojos. Sus reflexiones son fruto de la experiencia directa que ella hace trascender a ideas generales sobre la existencia humana: “... Todas las guerras habidas y por haber, son para mí, prueba irrecusable de la bancarrota espiritual de la Humanidad" (1916: 15), de este modo la autora señala el conflicto bélico como una falta de valores cristianos en la que la guerra es mala por sí misma y hace perder a los hombres sus valores de humanidad para volverlos animales.

La dirección del periódico, pese a ser aliadófilo, parece que valoró de forma positiva la expresión de una voz individual que subrayaba los valores "humanos" en contra de otras visiones periodísticas más "objetivas" o desapasionadas. La voz de una autora que además estaba sufriendo personalmente la posición de un país como Polonia cuya población estaba dividida entre el apoyo a Alemania y a Rusia. Además sus textos estaban plagados de detalles ya que era una gran observadora, no sólo de los sentimientos humanos, sino de la materialidad de la vida. Las alusiones a lo que ve son continuas: describe a los niños heridos, asustados, a los soldados enloquecidos, habla de la extensión de las enfermedades contagiosas, de la necesidad de inventar nuevas curas ante heridas nunca vistas, de los movimientos de las tropas, de las nuevas y terribles armas que se están comenzando a utilizar, del sufrimiento de los soldados al margen de su nacionalidad o de su condición social. Reflexiona sobre las nuevas técnicas de guerra que resultan un azote continuo no sólo a los militares sino a la población civil para la que el gas mostaza o las primeras bombas aéreas son la pesadilla. Una población indefensa cuya única opción es desplazarse de un lugar miserable a otro recorriendo una Europa devastada.

Sofía Casanova define la guerra como una falta moral que no tiene disculpa alguna. La llama "horrendo crimen" (1916: 26), un crimen de los gobiernos que es obsceno porque entierra juntos a "los vivos y los muertos" (1916:32); "bestializa a los hombres, ciega sus almas con un odio colectivo" (1916:53). No hay posibilidad de aceptar la guerra porque es un proceso al margen de toda racionalidad, y que niega las "leyes divinas y humanas" (1916: 127) en un "fragor de diabólicas pasiones desencadenadas" (1916: 304). En ningún caso hay justificación posible para que los gobiernos envíen a sus hombres a las guerras, que son instrumentos diabólicos para los poderosos. En los conflictos armados "Es Lucifer, el predilecto de los tiranos" el que gobierna el mundo (1916: 38).

Como para Tolstoi, en los principios cristianos está la base de la moralidad, "Y cuando unos y otros me llaman 'hermana' con menos amargura late mi corazón. Es dulcemente cristiano ese nombre; pero en estos horrores de la guerra, el cristianismo se ahoga en sangre" (1916:19). En la guerra no padecen sólo los seres humanos suje- 
tos a una moralidad laica, sino toda la serie de principios generales del cristianismo basados en la bondad y la ayuda los otros. Es esta una idea que Casanova a abandona nunca. Por ejemplo, cuando vuelve a España en 1919 y es recibida con grandes honores, el Centro del Ejército y la Armada le piden una conferencia sobre su experiencia de la guerra, que pronuncia en el Ateneo de Madrid el 25 de abril de ese año. En ella vemos cómo la autora se esfuerza en solicitar el beneplácito del auditorio, pero al mismo tiempo es inflexible en su idea de que nada justifica la guerra: "No hay victoria, no hay imperio o predominio de razas que justifiquen la destrucción del ser humano" (1919: 4). Como buena oradora, sabe disculparse o escudarse ante tan complicado auditorio en su condición de mujer: "Pobre mujer, aterrada por la catástrofe del mundo, yo tengo que decir, ante todo, que aborrezco la guerra, y que la actual, por concentrar en sí todos los males, con el pecado original del imperialismo, es un crimen de lesa civilización" (1919: 4). En esta conferencia es interesante la alusión que hace Casanova al principio de que sólo si existe la justicia social existe la paz. En clara alusión a la revolución rusa, afirma que ella es una persona que entiende que debe existir un orden social jerárquico, pero que debe ser justo con los más débiles ya que "... todo abuso de poder engendra sorda rebeldía de los maltratados" (1919: 8) y que la guerra había sido la que había empujado a Rusia a una revolución porque "las rebeliones populares surgen fácilmente en los osarios y en las tierras ensangrentadas de los campos de batalla" (10). La pobreza y la injusticia son las culpables de una revolución que Sofía Casanova no puede entender de ninguna manera, ya que contradice en el fondo sus principios católicos y su educación conservadora. Y la mejor garantía para que la revolución no tenga lugar es la justicia social: "Aquellas naciones que desarmen su ira con reformas de equidad social serán las menos amenazadas por el peligro rojo." (1919: 12).

\section{El papel de las mujeres en la guerra}

Casanova reflexiona a menudo sobre la guerra como un quehacer propio de los varones. La violencia no les es natural a las mujeres, y cuando surge, lo hace como algo completamente anormal, casi monstruoso y por supuesto nada deseable. La diferencia fundamental entre hombres y mujeres, es que ellas actúan y deben actuar en los conflictos armados como portadoras de la paz: "Séanos dado a las mujeres en todas partes, y en los terrenos de la lucha más aún, librarnos de influencias malsanas que nos impidan cumplir con nuestra misión de paz. " (1916: 53) Esta condición hermana de las mujeres, que se reconoce en el cuidado los otros, en la empatía con el dolor ajeno. Las mujeres son capaces de suspender sus juicios políticos para poner por encima de todo su capacidad de cuidados. Así la autora alaba "a las enfermeras polacas que cuidan a compatriotas y a rusos por igual..." Las mujeres se hermanan en los cuidados poniendo en suspenso la condición de "enemigos": "Como en el hospital acojo a todos los heridos y procuro su alivio, en estas páginas soy neutral, sincera, sin que mi corazón ni mi mente se inclinen ante ninguno de los dioses falsos de la destrucción" (1916: 59). La neutralidad en la ayuda a los otros no es un proceso 
de irracionalidad, sino una decisión voluntaria, una decisión ética que condicional su comportamiento frente los otros.

La condición de cuidadoras, impregna a todas las mujeres ya sean éstas de clase alta o baja. La diferencia es que Casanova nos va dando un auténtico rosario de nombres de mujeres que clase alta dedicadas a las tareas humanitarias, resaltando así la capacidad de servicio de estas mujeres acostumbradas, como ella misma, a una vida más cómoda y privilegiada. Nos habla de "la abnegada zarina", de la princesa Urusof que desentierra y acompaña el cuerpo de su hermano como si de Antígona se tratara para poderle dar sepultura en el hogar familiar. El texto está lleno de nombres propios de mujeres admirables por el sacrificio en los cuidados: la hermana Augustinowicz, Mira Awabiwban, Antonina Iwanowna, Antonina Afansjewa. Esa disposición femenina al servicio de los otros salta las fronteras y las ideologías "Acaso no falten en Bulgaria, Constantinopla y en los sitios donde se encuentran los Ejércitos aliados piadosas mujeres que mitiguen los sufrimientos de los heridos, y sean la paz de la guerra" (1916: 300).

A menudo reflexiona sobre su condición de mujer: "Pobre mujer, siento y creo que todas las conquistas logradas a costa de tan nefandos crímenes, de tan inconsolables dolores, no son buenas, ni han de traer suerte a las naciones que las han buscado." (1916: 39) Pero ¿qué pasa cuando las mujeres se sienten obligadas a participar en el conflicto tomando las amas? En este caso, Sofía Casanova se muestra inflexible: eso no es propio de las mujeres. En una carta publicada en el A $b c$ el 31 de agosto de 1917 presencia la llegada de las mujeres heridas que quedan de un batallón de 200 mujeres que han ido a las trincheras de Dwinsk, comenta: "Sólo un acto de desequilibrio social puede poner las armas del soldado en manos de mujeres y reglamentarlas, instruirlas y conducirlas a las líneas de fuego para que se batan como hombres". No es propio de mujeres la competitividad ni el reproche del comportamiento ajeno. Tampoco involucrarse pasionalmente en ningún sentido. Los heridos son heridos, sean del bando que sean. En un pasaje Casanova narra cómo ha sido amonestada por una compañera por cuidar con demasiado celo a un "enemigo" prusiano. Su compañera le reprocha: "No me pareced decente tanto flirtear con un prusiano". Ella simplemente comenta: "Casi me eché a reír. (...) Es la única mujer que he visto ciega por el odio, y hay que disculparla. El ardor mortífero de los hombres se contagia alguna vez al sexo débil..." (1916: 56-57).

Casanova muestra una gran modernidad cuando separa lo que son las estructuras sociales y el comportamiento de los individuos, dos dimensiones de la realidad en la que todo el ser humano vive. No todos los hombres son culpables y violentos, pero sí son dañinos todos los ejércitos que son en sí mismos estructuras perversas. "Yo creo que no hay violación, crimen, robo, infamia, de las que no sean capaces ALGUNOS soldados o jefes de todos los Ejércitos beligerantes. Si se ordena al soldado 'mata', que es lo más, ¿cómo exigirle que lo haga con cuidado, eligiendo los medios? 'Mata y triunfa', le ordenan, y él, para triunfar, mata, incendia, se hunde, se condena, borracho de coraje, de humo, de ímpetu atávico, animal, y el matador se hace héroe, se le glorifica..." (1916: 155) El problema no son los seres humanos, sino las estructuras 
que sustentan los conflictos bélicos, y el sentir social que habla de heroísmo en los actos de guerra.

La guerra es masculina, es negativa, y ella lo sabe por experiencia: "Yo sé, yo he visto de cuánto malo es capaz del hombre sajón, eslavo o latino enfurecido, bestializado en la guerra; el paroxismo de insensibilidad que lo empuja, desangrándose, moribundo a herir, a matar..." (1916: 158), y los niños no se salvan de ser instrumentalizados en la contienda. Nos cuenta la historia de un niño-soldado siberiano de trece años al que atiende en el hospital, y ante él, reflexiona: "Estremece la vida de esa criatura, su depravación de asesino legal a los trece años" (1916: 159). Para Sofía Casanova los seres humanos no son los perversos, porque ella está contando todos los días cómo todos se humanizan e igualan cuando existe el dolor y el sufrimiento. Lo que le da una gran modernidad a sus textos, es la idea de que lo perverso está en las estructuras de poder, en los gobiernos o las formas políticas que exaltan los valores de la guerra.

\section{Conclusiones}

En este texto hemos intentado ir más allá de la realización de una semblanza de una de las mujeres destacables en la historia de España por haber sido la primera mujer reportera durante muchos años, y que cubrió tres de los grandes conflictos europeos de principios del siglo XX. Nos ha interesado destacar en este trabajo el valor teórico y de pensamiento sobre los valores pacifistas que Sofía Casanova se atrevió a exponer en un tiempo en el que el pensamiento dominante era no cuestionar la guerra, sino la necesidad de alinearse pasionalmente a uno u otro bando. Para ello, hemos recurrido al análisis muy concreto de una de sus obras: De la guerra. Crónicas de Polonia y Rusia publicada en 1916 y que recogía las crónicas enviadas al diario $A b c$ en los primeros años de la I Guerra Mundial.

Nos ha interesado especialmente indicar que el trabajo de Sofía Casanova debe entenderse en unas claves temporales concretas: finales del siglo XIX y principios del siglo XX, un momento en el que las mujeres habían conseguido participar en la prensa del momento y luchaban activamente a favor de sus derechos políticos. No debemos conformarnos con los trabajos sobre mujeres "pioneras" que borran el contexto en el que las mujeres realizaron su obra creativa. Ni la creación literaria ni artística se produce en el vacío cultural. Por eso ha sido importante para nosotros relacionar las ideas de la autora sobre el pacifismo y el anti-militarismo con la situación política e ideológica que se vivía en torno a los inicios de la I Guerra Mundial. 


\section{Referencias Bibliográficas}

ALAYETO, Ofelia (1992), Sofia Casanova (1861-1958): Spanish Poet, Journalist and autor, Maryland: Scripta Humanistica

BERNÁRDEZ RODAL, a. (Dir.) (2007) Escritoras y periodistas en Madrid (18761926), Madrid: Ayuntamiento de Madrid.

BUGALLAL Y MARCHESI, José Luis (1964) Sofía Casanova. Un siglo de glorias y dolores, Litografía e Imprenta Roel: La Coruña.

CASANOVA, Sofía, La mujer española en el extranjero, Madrid, 1910 Conferencia dada en el ateneo de Madrid el 9 de abril de 1910.

--- (1919) "Impresiones de una mujer en el frente Oriental de la guerra europea", Centro del Ejército y la Armada, Madrid. Conferencia leída el 25 de abril de 1919

--- (1916) De la guerra. Crónicas de Polonia y Rusia. Madrid, R. de Velasco.

HOOPER, Kirsty (2008), Sofia Casanova, a Spanish Writer in the European Fin de Siécle, Tennessee: Vanderbilt University Press.

LERMA RUEDA, Antonio y MARTÍN POLÍN, Raquel y (2007) “Ante todo ciudadanas. Prensa y voto a través de la prensa madrileña (1900-1931), en MO ROMERO, Esperanza (Coord.) La voz de las mujeres: la prensa madrileña y los discursos de género (1740-1931), Madrid: Ayuntamiento de Madrid. Págs. 122-166.

LORENZO ARRIBAS, Josemi (2007) "Tensiones militarismo/ antimilitarismo" en BERNÁRDEZ RODAL, Asunción (Dir.) (2007) Escritoras y periodistas en Madrid (1876-1926), Madrid: Ayuntamiento de Madrid. Págs. 125- 162.

MAGALLÓN PORTOLÉS, Carmen (2006) Mujeres en pie de paz. Pensamiento y prácticas, Madrid: Siglo XXI.

MARTÍNEZ MARTÍNEZ, Rosario (1999) Sofia Casanova, mito y literatura. Santiago de Compostela: Xunta de Galicia.

OSORIO, Olga, (1997) Sofia Casanova, Xunta de Galicia

PAZOS, Antón (Coord.) (2010) Vida e tempo de Sofía Casanova (1861-1958), Santiago de Compostela: Instituto de Estudios Galegos "Padre Sarmiento".

PERINAT, Adolfo y MARRADES, Ma Isabel (1980), Mujer, prensa y sociedad en España 1800-1939, Madrid: Centro de Investigaciones Sociológicas.

RIUS GATELLI, Rosa (ed.) (2006) Sobre la guerra y la violencia en el discurso femenino (1914-1989) Barcelona: Universidad de Barcelona.

ROCH CASTELLANOS, Mercedes (1977), La mujer y la prensa. Desde el siglo XVII a nuestros días. Madrid: Edición propia.

SCANLON, Geraldine M., (1986) La polémica feminista en la España contemporánea (1868-1974) Madrid: Akal.

SIMON-PALMER, Ma del Carmen (1991) Escritoras españolas del siglo XIX: manual bio-bibliográfico, Madrid: Castalia. Págs. 530-552.

WARD, Paul (2001) "Women of Britain Say Go: Women's Patriotism in the First World War" en Twentieth Century British History, 12/1, pp. 23-45. 


\section{Notas}

1 Vid por ejemplo la página del Centro de Investigaciones por la paz. http://www.centropaz.com.ar/ radio08-03-11.html

\section{La autora}

Asunción Bernárdez Rodal es Profesora Titular de la Universidad Complutense de Madrid de Semiótica de los Medios de Masas, Teoría de la Información y Comunicación y Género, asignaturas que imparte en la Facultad de Ciencias de la Información.

Licenciada en Filología Hispánica y Doctorada en Periodismo, en la actualidad dirige el Instituto de Investigaciones Feministas de la Universidad Complutense. Ha formado parte de la comisión de expert@s para la violencia de género en los medios de comunicación del Ministerio de Igualdad.

Sus trabajos de investigación han girado entorno a los análisis de los discursos de género tanto textuales como audiovisuales. En especial ha desarrollado una línea de investigación entorno al cine y los análisis de la violencia. Ha publicado el libro Violencia de género en el cine español en la Editorial Complutense, y ha desarrollado otras líneas de trabajo sobre textos literarios y la experiencia creativa de las mujeres como recogidos en los libros Escritoras y periodistas en Madrid, publicado en el Ayuntamiento de Madrid Perdidas en el espacio en la editorial Huerga \& Fierro, El humor y la risa en la Fundación Autor, y en la actualidad ha publicado más de cincuenta artículos especializados en género y comunicación. En los últimos años ha desarrollado una línea de investigación sobre Museos y Arte de mujeres dentro del grupo de Investigación del Instituto de Investigaciones feministas y ha publicado el libro colectivo: López Fdez. Cao, Marian y Fernández Valencia, Antonia y Bernárdez Rodal, Asunción (2012) El protagonismo de las mujeres en los museos. Editorial Fundamentos, Madrid. 